\title{
ASSISTÊNCIA PRÉ-NATAL E ACOLHIMENTO SOB A ÓTICA DE GESTANTES NA ATENÇÃO PRIMÁRIA À SAÚDE: ESTUDO QUALITATIVO
}

\author{
PRENATAL CARE AND RECEPTION UNDER THE PERSPECTIVE OF PREGNANT \\ WOMEN IN PRIMARY HEALTH CARE: QUALITATIVE STUDY
}

\author{
Camila Ramos Batista ${ }^{1}$ Floriacy Stabnow Santos ${ }^{2}$ Francisca Jacinta Feitoza de Oliveira $^{3}$ \\ Livia Fernanda Siqueira Santos ${ }^{4}$ Livia Maia Pascoal ${ }^{5}$ Ana Cristina Pereira de Jesus Costa ${ }^{6}$ \\ Marcelino Santos Neto ${ }^{7}$
}

\begin{abstract}
RESUMO
Objetivo: Este estudo objetivou conhecer a percepção das gestantes de baixo risco frente à assistência pré-natal e ao acolhimento prestado em uma Unidade Básica de Saúde. Métodos: Pesquisa qualitativa, na qual foram realizadas 21 entrevistas entre abril e julho de 2019 em uma Unidade Básica de Saúde na Região Nordeste. Pela análise de conteúdo, emergiram quatro categorias: Pré-natal e sua importância; Qualidade da assistência no pré-natal; A (in)satisfação com o acolhimento recebido; Acolhimento e mudanças necessárias. Resultados: A maioria das gestantes se mostrou satisfeita e aprovou o atendimento recebido, em especial do profissional enfermeiro, tanto no aporte teórico, como em procedimentos técnicos, como no acompanhamento da vitalidade fetal e de esquemas medicamentosos. Em contrapartida, as gestantes não se encontram acolhidas na unidade de saúde, e relataram demora no atendimento e falta de empatia por parte de alguns profissionais. Considerações finais: É de extrema importância que os profissionais envolvidos no atendimento proporcionem o apoio necessário à mulher em seu processo gravídico, desde a adesão e continuidade de seu pré-natal, até a reorganização psíquica quanto ao vínculo com o bebê, nas mudanças corporais e na retomada do planejamento familiar.
\end{abstract}

Palavras-chave: Acolhimento; Assistência Pré-Natal; Gestante; Atenção Primária a Saúde

\begin{abstract}
ABASTRACT
Objective: This study aimed to know the perception of low-risk pregnant women in the face of prenatal care and the reception provided in a Basic Health Unit. Methods: Qualitative research, in which 21 interviews were conducted between April and July 2019 in a Basic Health Unit in the Northeast Region. Through content analysis, four categories emerged: Prenatal care and its importance; Quality of prenatal care; A (in)satisfaction with the reception received; Reception and necessary changes. Results: Most pregnant women were satisfied and approved the care received, especially from the nursing professional, both in the theoretical contribution, as in technical procedures, as well as in the monitoring of fetal vitality and drug regimens. On the other hand, pregnant women are not welcomed to the health unit, and reported a delay in care and lack of empathy on the part of some professionals. Final considerations: It is extremely important that the professionals involved in the care provide the necessary support to the woman in her pregnancy process, from the access and continuity of her prenatal care, to the psychic reorganization regarding the bond with the baby, in the body changes and in the resumption of family planning.
\end{abstract}

Keywords: User Embracement; Prenatal Care; Pregnancy; Primary Health Care

\footnotetext{
1 Enfermeira, graduada pela Universidade Federal do Maranhão. Orcid: https://orcid.org/0000-0002-5134-321X Email: camilabatistar@outlook.com

${ }^{2}$ Enfermeira, Doutora em Ciências. Professora Adjunta da Universidade Federal do Maranhão (UFMA) no Curso de Graduação em Enfermagem, na Pós-graduação em Saúde e Tecnologia (PPGST). Orcid: http://orcid.org/0000-0001-78407642floriacys@gmail.com

${ }^{3}$ Enfermeira, Mestre em Saúde Baseada em Evidências. Professora Assistente da Universidade Federal do Maranhão no Curso de Graduação em Enfermagem. Orcid: https://orcid.org/0000-0002-3226-6917 Email: jacinta_feitoza@ hotmail.com

${ }^{4}$ Enfermeira, Especialista em Saúde da Família. Mestranda do Programa de Pós-graduação em Saúde e Tecnologia da Universidade Federal do Maranhão. Orcid: https://orcid.org/0000-0001-9492-0091Email: livia-siqueira2011 @ hotmail.com

${ }^{5}$ Enfermeira, Doutora em Enfermagem, Professora Adjunta da Universidade Federal do Maranhão (UFMA) no Curso de Graduação em Enfermagem, na Pós Graduação em Saúde e Tecnologia (PPGST) e Enfermagem (PPGENF). Orcid: https://orcid.org/0000-00030876-3996 Email: livia mp@ hotmail.com

${ }^{6}$ Enfermeira, Doutora em Enfermagem. Professora Adjunta da Universidade Federal do Maranhão (UFMA) no Curso de Graduação em Enfermagem e na Pós-graduação em Saúde e Tecnologia (PPGST). Orcid: https://orcid.org/0000-0001-7757-8183 Email: anacristina_itz@hotmail.com

${ }^{7}$ Farmacêutico Bioquímico, Doutor em Ciências. Professor Adjunto da Universidade Federal do Maranhão (UFMA) no Curso de Graduação em Enfermagem, na Pós-graduação em Saúde e Tecnologia (PPGST) e na Pós-graduação em Enfermagem (PPGENF). Orcid: https://orcid.org/0000-0002-6105-1886 Email: marcelinosn@ gmail.com
} 


\section{INTRODUÇÃO}

A atenção pré-natal (APN) é um conjunto de ações realizadas durante $\mathrm{o}$ período gestacional visando ao atendimento global da saúde da mulher de maneira individualizada, oferecendo sempre qualidade e resolutividade durante todo o processo ${ }^{(1)} \mathrm{e}$ tem como meta garantir o desenvolvimento gestacional, bem como a saúde da mãe e da criança, assegurando o parto e o pós-parto saudáveis.

Desse modo, o acolhimento à gestante na Atenção Primária implica na responsabilização da equipe de saúde em promover atenção integral e resolutiva, valorizando as preocupações, as angústias e os medos da mulher ${ }^{(2)}$, além de se encontrar em consonância com a estratégica Rede Cegonha, implantada paulatinamente no Brasil desde 2011, que objetiva assegurar às mulheres o direito ao planejamento reprodutivo e a atenção humanizada à gravidez, ao parto e ao puerpério, bem como assegurar às crianças o direito ao nascimento seguro e ao crescimento e desenvolvimento saudáveis ${ }^{(3)}$.

Para as mulheres usuárias do Sistema Único de Saúde (SUS) no Brasil, a APN, é hodiernamente desenvolvida na Estratégia Saúde da Família (ESF) e baseia-se no acolhimento, no cuidado, na educação em saúde e na humanização, sendo constituída por equipes multiprofissionais compostas minimamente por médico, enfermeiro, auxiliar de enfermagem e os agentes comunitários de saúde, que desempenham papel importante na consolidação dos princípios dessa estratégia, principalmente no que trata da captação das gestantes na comunidade para iniciar o pré-natal ${ }^{(4)}$.

Os profissionais dessa equipe devem estar preparados para atuar, atualizando e aprofundando continuamente seus conhecimentos $^{(5)}$, de maneira a garantir a humanização da assistência prestada à gestantes, como proposto pelo Programa de Humanização no Pré-natal e Nascimento. O enfermeiro deve ter percepção sensível quanto à importância de humanizar e qualificar a atenção à gestante, no intuito de obter sua maior adesão ao pré-natal, garantindo qualidade na assistência e resultados obstétricos e perinatais, possibilitando a identificação precoce de intercorrências ${ }^{(6,7)}$.

Diante dessas considerações, acreditase que as ações do enfermeiro são importantes no pré-natal, uma vez que por meio da assistência prestada, é possível identificar intercorrências precocemente e monitorar as gestantes que se encontram em situações de riscos. Além disso, as gestantes podem se sentir mais acolhidas diante das descobertas advindas em cada semana de gestação, proporcionando assim, uma gravidez mais segura.

Um atendimento adequado ao pré- 
natal não se resume a ações isoladas e pontuais, devendo ser atravessado por processos de responsabilização, buscando a criação de vínculo a partir da escuta de problemas, troca de informações, mútuo reconhecimento de direitos e deveres, e decisões que possibilitem intervenções pertinentes e eficazes em torno das necessidades dos usuários do serviço de saúde ${ }^{(8)}$.

A APN, em território nacional brasileiro, é regida pelas diretrizes do Programa de Humanização no Parto e Nascimento, instituído pelo Ministério da Saúde, que se fundamenta na humanização da assistência como condição para o adequado acompanhamento da gestação, parto e puerpério, buscando assistência completa de qualidade, qualificada e humanizada, tornando-se fundamental para a saúde materna e neonatal, e visando à prevenção de intercorrências indesejáveis ${ }^{(8)}$.

A garantia de um pré-natal de qualidade, que prime pelos direitos da gestante e da criança, é essencial e caracteriza-se como um dos enormes desafios relacionados à atenção à saúde da mulher, tanto na esfera gerencial quanto assistencial ${ }^{(3)}$. Nesse contexto, a relevância de práticas humanizadas, como o acolhimento, ganha destaque no cenário nacional, visto o impacto dessa prática nos serviços de saúde, como importante ferramenta para a construção de prestação de serviços públicos de atenção à saúde de mais qualidade ${ }^{(8)}$.

A proposta de atendimento qualificado à gestante até então é importante desafio ao SUS, muito embora a assistência pré-natal alcance cobertura praticamente universal, sendo perceptível a persistência de desigualdades no acesso ao cuidado adequado, com potencial de reverter indicadores perinatais desfavoráveis ${ }^{(9)}$. Dessa maneira, urge a necessidade de uma equipe multiprofissional com formação ampla e atualizada no que diz respeito à temática da humanização, que assimilem e incorporem mudanças no cenário de atenção à saúde da mulher, tendo uma atuação que respeite as especificidades de cada profissional, gerando um bem comum a paciente assistida ${ }^{(10)}$.

Considerando os aspectos contextuais supracitados, apreender as percepções das gestantes usuárias da Atenção Primária à Saúde sobre a assistência pré-natal com foco no acolhimento a elas dispensadas durante o pré-natal é de notoriedade singular, tendo em vista que denota uma concepção ampliada sobre as práticas e atitudes dos profissionais envolvidos nesse acompanhamento e podem nortear a implementação de melhorias do atendimento prestado pela equipe de saúde.

Pressupõe-se que o acolhimento tem sido praticado no atendimento à gestante na Atenção Primária à Saúde proporcionando uma assistência adequada e de qualidade. Desse modo, o objetivo desse estudo foi conhecer a percepção das gestantes de baixo 
risco frente à assistência pré-natal e ao acolhimento prestado em uma Unidade Básica de Saúde (UBS).

\section{MÉTODOS}

Trata-se de uma pesquisa descritiva exploratória com abordagem qualitativa. A pesquisa descritiva é aquela que descreve uma realidade, e o método qualitativo tem como propósito a compreensão de fenômenos dentro de determinadas circunstâncias, considerando os significados transmitidos pelos participantes da pesquisa bem como dos elementos e especificidades que os envolvem $^{(11)}$

A pesquisa foi realizada em uma unidade básica de saúde (UBS) no município de Imperatriz-MA, no sudoeste maranhense, nordeste do Brasil, no período de abril a julho de 2019, estando atrelada às ações de extensão realizadas por meio do "Projeto Acolher" do curso de enfermagem da Universidade Federal do Maranhão.

As participantes do estudo foram abordadas de forma intencional dentre as que aguardavam a consulta pré-natal, culminando, após saturação dos dados ${ }^{(12)}$ em 21 gestantes em diferentes períodos gestacionais, quando os depoimentos não mostraram nenhuma nova informação.

Foram incluídas, nesta pesquisa, gestantes maiores de 18 anos, primíparas e multíparas em qualquer trimestre gestacional, realizando pré-natal de baixo risco na UBS, cadastradas no Sistema de Acompanhamento do Programa de Humanização no Pré-Natal e Nascimento (SISPRENATAL) e com capacidade civil ou legal para dar seu consentimento livre e esclarecido. Foram excluídas gestantes com algum distúrbio ou patologia que dificultasse a comunicação e as impedisse de responder à entrevista.

A coleta dos dados foi realizada por entrevista semiestruturada $\operatorname{adaptada}^{(9)}$, e gravadas após anuência das participantes, cujo roteiro foi composto por três partes: a primeira, com questões objetivas referentes ao perfil sociodemográfico das participantes como idade, escolaridade, estado civil, renda familiar e histórico obstétrico; a segunda, com questões abertas inerentes à assistência de enfermagem atual recebida; e a terceira com questionamentos que incitam expressar percepções sobre o acolhimento recebido durante os atendimentos.

Adotaram-se as seguintes questões norteadoras: Como você avalia o atendimento ofertado pelo enfermeiro durante o pré-natal? O pré-natal faz diferença para você, sua saúde e a saúde do seu filho? Como é sua experiência em relação ao acolhimento? O que você mudaria no atendimento?

A avaliação da assistência pré-natal foi direcionada para atuação do profissional enfermeiro pelo fato de ser o profissional que realiza o acompanhamento desta clientela na maioria das consultas, e as ações de acolhimento foram para todos os funcionários 
que realizaram atendimentos às gestantes entrevistadas.

As entrevistas foram realizadas individualmente em sala reservada, após assinatura do Termo de Consentimento Livre e Esclarecido (TCLE), com duração de aproximadamente 20 minutos, e as falas foram gravadas em um smartphone, sendo transcritas na íntegra e posteriormente analisadas.

Para a diferenciação dos sujeitos da pesquisa, assim como a preservação de sua identidade, as participantes foram identificadas aleatoriamente com a letra ' $G$ ' seguida de numeral arábico, que indicou a ordem na qual as entrevistas aconteceram.

Para a análise e interpretação dos dados qualitativos, utilizou-se a técnica de análise de conteúdo de $\operatorname{Bardin}^{(13)}$ compreendendo uma fase de pré-análise e exploração dos dados onde se buscou conhecer o conteúdo das falas, seguida da organização sistemática dos dados que foram identificadas em categorias, com descrição detalhada das características pertinentes e, por fim, a conclusão, por meio dos dados obtidos.

Após intensa leitura do material e análise dos dados coletados, emergiram quatro categorias: Pré-natal e sua importância; Qualidade da assistência no pré-natal; A (in)satisfação com o acolhimento recebido; Acolhimento e mudanças necessárias.

O desenvolvimento do estudo foi realizado em conformidade com $\mathrm{o}$ preconizado pela Resolução nº466/2012 do Conselho Nacional de Saúde. O projeto foi aprovado pelo Comitê de Ética em Pesquisa com seres humanos da Universidade Federal do Maranhão (parecer 1824976/2016).

\section{RESULTADOS}

No tocante às características sociodemográficas, as participantes do estudo tinham idade média de 24 anos, variando entre 18 a 34 anos. Tinham Ensino Fundamental 6 mulheres (28,6\%), Ensino Médio 14 mulheres $(66,6 \%)$ e $1(4,8 \%)$ tinha Ensino Superior incompleto. Quanto ao estado civil, $7(33,4 \%)$ eram solteiras e 14 $(66,6 \%)$ casadas. No que tange às ocupações, 11 afirmaram ser donas de casa $(52,3 \%), 4$ $(19,0 \%)$ eram estudantes, $6(28,7 \%)$ tinham emprego formal. A renda familiar das participantes, neste contexto, variava de 1 a 3 salários mínimos, ressaltando que a maioria vivia com apenas 1 salário mínimo.

Em relação à situação e ao histórico obstétrico, $11(52,3 \%)$ eram multíparas e 10 $(47,7 \%)$ eram primíparas. A idade gestacional, no momento da participação do estudo, variou de 12 a 39 semanas, com todas as gestações de feto único. Referente ao planejamento familiar, $12(57,1 \%)$ eram gestações planejadas e $9(42,9 \%)$ eram não planejadas. No que diz respeito às multíparas, apenas $1(4,7 \%)$ teve aborto anteriormente, 3 $(14,3 \%)$ tiveram seus partos por cesariana, 6 $(28,5 \%)$ por parto vaginal e $2(9,5 \%)$ tiveram 
tanto parto normal como cesáreo.

\section{Categoria 1 - Pré-natal e sua importância}

A percepção das gestantes quanto à realização do pré-natal, no decorrer de sua trajetória gravídica, bem como os impactos decorrentes desse acompanhamento evidencia a importância do cumprimento de um prénatal de maneira adequada.

Sem dúvidas, ajuda bastante. É... por que eu acho, sei lá, eu no começo eu tive muitas dúvidas, né, aí a enfermeira sempre me orientou a fazer as coisas certas, a tomar as vitaminas, é... passou exames pra mim saber como ele (feto) tá, e eu gostei. [G3]

O pré-natal é essencial, que toda grávida tem que ter, né, porque se não tiver o pré-natal o menino pode nascer com deficiência e tem que ter, né. [G10]

Durante as entrevistas, as participantes além de saberem da necessidade de realizar o pré-natal, relataram que aderiram e mantiveram a periodicidade das consultas proposta pelos profissionais (enfermeiro e médico).

Porque eu acho que cada mês, né, dá pra saber, a gente descobre uma coisa diferente, né, tanto com os ultrassons, os exames né, dá pra saber se o bebê tá bem ou não. [G4]

Então, qualquer coisa que eu sinto eu procuro logo o posto, o enfermeiro, pra saber logo o que tá acontecendo, eu não deixo agravar muito não, eu tenho medo que prejudique a criança. Eu não falto. [G20]

$\mathrm{Na}$ abordagem acerca dos elementos presentes em um acompanhamento de prénatal adequado, como a realização de exames hematológicos/sorológicos, orientações e suplementação polimineral, percebeu-se a valorização de tais condutas, por partes das entrevistadas.

Sim, por que ela (enfermeira) indica as atividades pra fazer em casa, tipo como eu tenho edema aí ela fala o que eu tenho que fazer, as massagens" [G5]

Eu fiz vários exames, aí descobri umas coisas que eu não tinha, aí passou as medicações certas... [G6]

Tá (risos). É por que ela informa a gente, né, o que é bom pra gente comer, o que é pra gente fazer, a gente vai fazendo o que ela manda, aí vai melhorando, né, pra mim e pro meu filho, acho que é isso (risos). [G12]

\section{Categoria 2:- Qualidade da assistência no} pré-natal

Ao serem questionadas, em termos da qualidade do serviço de pré-natal ofertado, o que incluía, a priori, o atendimento realizado pelo profissional enfermeiro, observou-se satisfação das 
usuárias.

Eh... é bom, né, aqui...atendem agente bem, explica direito as coisas. [G1]

A enfermeira atende a gente muito bem, perguntam o que a gente tá sentindo, essas coisas. [G2]

A enfermeira é... bom, o atendimento é bom, nos acolhe bem, trata a gente bem, super bem na verdade. [G4]

Ai eu achei ótima a enfermeira! Ela dá bronca quando precisa dar bronca, explica o que tem que explicar, eu gostei muito do atendimento dela! [G13]

A enfermeira daqui eu não tenho nada que falar, tudo que eu não preciso nem perguntar a enfermeira já vem com todas as dúvidas tirando. $E$ até no momento eu não tenho o que reclamar não. [G16]

Algumas das participantes ainda aliaram a qualidade dos serviços prestados à realização de determinadas atividades, como exame físico, prescrições e orientações realizadas durante as consultas de enfermagem.

É bom o atendimento dela, ela é muito simpática e ouve a gente, ela ouve bem, bom, pra mim eu gosto. A enfermeira para mim está sendo boa. Da última vez ela mediu a barriga, tentou ouvir o coraçãozinho, tá bom pra mim. [G7]

Ah é bom, eles dão muita atenção, fazem muitas perguntas, gostei do atendimento daqui. Tiram minhas dúvidas. Eu gosto mais da enfermeira, ela pergunta mais, e o médico não pergunta muito. Olha o coração da criança, meu peso, vê se está tudo ok, se não tem nenhuma anemia, nenhuma vacina atrasada, aí libera pra outra data, passa o medicamento, quando precisa. [G18]

\section{Categoria 3: A (in)satisfação com o} acolhimento recebido

No tocante ao acolhimento dispensado durante o pré-natal por parte da equipe de saúde, relacionado à maneira como percebiam e avaliavam o acolhimento oferecido durante o atendimento, algumas gestantes expressaram insatisfação.

Não quero comprometer os profissionais de saúde (risos)... (...)Aí, não são todos as pessoas aqui que acolhem a gente bem né? $10 \%$ aí têm que melhorar bastante no atendimento. [G4]

Por alguns profissionais sim, outros não. Não é recebido assim, com um bom dia, né, do jeito que a gente gostaria que fosse, entendeu? Mas de alguns profissionais a gente gosta muito. [G5]

$\mathrm{Na}$ recepção eles já deixam um pouco a desejar, não sei se é por que também é pouca gente, pra acolher, pra atender tanta gestante, né? Eu acho um pouco demorado, eles não têm... tipo... não sei, não sei se é por que tem pouca gente, pouca pessoa que atende, né, a gente espera muito, e vai pra um lado e vai pra outro, 
a gente nunca sabe aonde é que fica o lugar certo, eles deixam um pouco a desejar nessa parte. [G7]

Assim... nem sempre, porque às vezes quando a gente vem aqui pedir informação, pra fazer qualquer coisa, eles tratam a gente como muito descaso as vezes, durante essa minha gravidez até que eu não tô sentindo tanto não. [G8]

Considerando ainda esta ótica, as participantes, apesar de se mostrarem insatisfeitas com o acolhimento, relataram que se sentiam bem acolhidas no momento específico das consultas, em especial, se realizadas com o profissional enfermeiro.

É bom o atendimento da enfermeira, ela é muito simpática $e$ ouve a gente, ela ouve bem, bom, pra mim eu gosto. [G7]

É igual eu te falei, pela enfermeira, ela é super gente boa, né, mas as outras aqui fora não sabem de nada, se a gente perguntar algumas coisas elas não sabem informar... aí a gente tem que esperar ela mesmo pra se quiser fazer alguma pergunta, perguntar pra ela. [G12]

\section{Categoria 4: Acolhimento e mudanças necessárias}

Além de relatarem suas insatisfações, as inquiridas pontuaram alguns aspectos que sinalizou a necessidade de mudanças, no intuito de melhorias relacionadas à qualidade do acolhimento. Assim, pontuaram categoricamente que a demora no atendimento é ponto a ser revisto.

Pra ser... mais ligeiro, porque demora muito. Custa assim um pouco, num tem? Assim, a gente fica esperando, só. [G2]

Eu mudaria tanta coisa, pra eles atenderem a gente mais rápido, porque tem hora que demora demais e é isso. [G2]

A organização, sei lá, tem hora que as filas ficam todas bagunçadas. E também, assim, na hora de marcar, né, o exame, as mulheres tem vez que demora marcar, a gente fica horas e horas na fila esperando elas chegarem, pra gente marcar. [G12]

Neste seguimento, não somente a demora de atendimento foi relatada como algo a ser melhorado no serviço, mas também a empatia e a atenção dada pelos profissionais às participantes.

Mais simpatia das pessoas, com certeza. [G3]

É como eu estava te falando, conversaria um pouquinho mais com as pessoas. [G4]

Acho que deve melhorar mais na atenção, eu comecei com uma enfermeira e vou terminar com outra. A primeira era tão simpática e atenciosa essa nova eu já não sinto isso. [G20]

\section{DISCUSSÃO}

O pré-natal é fundamentalmente visto com a função de acolher a mulher desde o 
início da gravidez, garantindo, ao término dela, o nascimento de um recém-nascido salutífero, assim como a plena saúde materna, sendo finalizado somente após a consulta de puericultura e puerpério ${ }^{(14)}$. É necessário valorizar a opinião da mulher durante as decisões e o desenvolvimento do plano terapêutico, individualizando o cuidado e valorizando as subjetividades, fomentando a interação entre o profissional e a gestante ${ }^{(15)}$.

No intento de ser realizado com qualidade, é primordial a construção de uma nova percepção sobre o processo saúde/doença, que considere os mais diversos âmbitos da vida da mulher, seja no econômico, no cultural, no físico e no social em que se encontra ${ }^{(16)}$.

Estão previstas, pelo manual técnico do pré-natal e puerpério, do Ministério da Saúde, no mínimo, se gestação classificada como baixo risco, seis consultas durante o período de gravidez, sendo uma consulta no primeiro trimestre de gestação, duas no segundo e três no terceiro. O início precoce da assistência pré-natal é indicado para que se façam possíveis diagnósticos e a identificação de riscos ligados à saúde materna e fetal ${ }^{(14)}$. As estratégias utilizadas pelos profissionais de saúde não somente no início, mas ao longo de todas as ações previstas durante o pré-natal, visam prevenir e controlar doenças, e manter o bem-estar do quadrinômio mãe-bebêfamília-comunidade, com vistas à atenuação dos índices de morbimortalidade materna e infantil $^{(1)}$.

Devem ser realizadas as solicitações dos exames de rotina e complementares de primeiro e terceiro trimestre; e recomendações de vacinas; orientações diversas sobre atividades profissionais, físicas, educativas, visitas domiciliares, entre outras $^{(17)}$. A mulher deve receber informações, inclusive, sobre exercícios respiratórios e dicas sobre o reconhecimento dos sinais de parto ${ }^{(16)}$.

As consultas de pré-natal, que devem ser intercaladas entre enfermeiro e médico, focam nos aspectos educativos, os quais possibilitam às gestantes espaços para expressarem seus medos, angústias, incertezas e dúvidas sobre as modificações que acontecem com o próprio corpo, permitindo esclarecimentos mediante orientações pertinentes ao ciclo gravídico-puerperal ${ }^{(18)}$. Dessa forma, as ações educativas devem ultrapassar o modelo biomédico, no intuito de valorizar as reais necessidades da gestante.

Alguns fatores ajudam no sucesso do acompanhamento pré-natal, entre eles o interesse e a participação da gestante e de seus familiares; a participação dos órgãos assistenciais responsáveis por essa assistência; e a forma como os profissionais de saúde atuam durante a atenção, sendo este fator decisivo para a qualidade do acompanhamento à gestante, com competência, dedicação e de forma humanizada ${ }^{(7)}$. 
É requisito de uma assistência prénatal de qualidade uma equipe de saúde sensibilizada para a importância da orientação junto à gestante, permitindo que esta não desista do acompanhamento durante o prénatal $^{(6)}$. Um pré-natal realizado de forma adequada possibilita esclarecer aspectos como aleitamento, sinais de trabalho de parto e alimentação saudável, norteando as mulheres sobre os cuidados que elas devem ter com sua saúde e o recém-nascido, durante esse período.

A qualidade assistencial durante o prénatal detém-se não somente às ações mencionadas nas falas, mas vai além do esclarecimento de dúvidas, no sentido de preocupar-se com os anseios e os medos trazidos pelas gestantes ${ }^{(1)}$. O profissional enfermeiro envolvido na assistência deve atuar de forma que os cuidados pré-natais transcendam os aspectos biológicos, acompanhando as gestantes em todas suas emoções. Ainda, a garantia de uma assistência satisfatória deve prevenir, diagnosticar e tratar eventualidades indesejáveis, que possam se processar durante a gestação ${ }^{(19)}$. Assim, os profissionais de enfermagem detêm importante papel no pré-natal ao desenvolverem ações educativas em saúde, prevenindo, protegendo, recuperando e promovendo a saúde ${ }^{(20)}$.

No que tange a (in)satisfação com o acolhimento recebido, tal insatisfação denota a possibilidade de interferência na adesão no processo de um acompanhamento do prénatal. Nesse sentido, o acolhimento no prénatal deve resultar na recepção da mulher na unidade de saúde, responsabilizando-se por ela, ouvindo suas queixas, permitindo que expresse suas preocupações e angústias, garantindo atenção resolutiva e articulação com os outros serviços de saúde, e promovendo a continuidade da assistência, quando necessário ${ }^{(16)}$. O diálogo franco e a sensibilidade dos profissionais que acompanham o pré-natal são condições básicas para que o saber em saúde seja disposto à mulher, protagonista no processo de gestação e parto.

$\mathrm{O}$ acolhimento organiza o processo de trabalho e constitui o principal meio para atender o usuário de forma a ter uma escuta qualificada, em que o profissional busca responder suas necessidades ${ }^{(21)}$.

Em um estudo realizado em Ilhéus (BA), as gestantes se mostraram satisfeitas com a assistência do enfermeiro no pré-natal, ao relatarem práticas de cuidado que privilegiavam a escuta e o acolhimento dessa profissional da saúde, no que se refere ao binômio mãe e filho, superando o modelo de cuidar frio e impessoal - realidade essa semelhante em nossa casuística ${ }^{(17)}$.

O profissional enfermeiro permite à usuária uma consulta com características mais humanizadas, focada na individualidade e na atenção, baseada na 
escuta de qualidade $^{(16)}$. Tal prática potencializa a adesão ao serviço e o entendimento da importância das ações de saúde, facilitando a detecção precoce de eventuais complicações e tornando a prática de cuidado compartilhada durante todo seu ciclo gestacional.

Visando um acolhimento adequado, é necessária uma reorganização do modelo assistencial ofertado pelos serviços de saúde, para melhorar a satisfação dos usuários, e o acolhimento é um dos fatores nessa reforma assistencial, atendendo à proposta do programa nacional de humanização, oferecendo às usuárias dos serviços de saúde uma prática diferenciada no que diz respeito ao atendimento, considerando-se suas subjetividades e as compreendendo em suas demandas e necessidades, e garantindo uma assistência feita de modo eficaz e resolutivo $^{(19)}$.

Um serviço de saúde de qualidade deve criar opções para evitar longas esperas e priorizar as gestantes nas filas, constituindo-se um direito de cidadania ${ }^{(5)}$. Além de produzir incômodo, a longa espera pode estabelecer-se como empecilho para a frequência da gestante nas consultas prénatais e não assegura às gestantes o direito à atenção de fácil acesso.

A equipe torna-se responsável pela situação de saúde dos usuários, e isto se evidencia não apenas no momento do atendimento propriamente dito, mas também a partir do momento em que se forma um elo entre o serviço e a população usuária ${ }^{(21)}$.

O acolhimento é uma postura ética, que exige saberes e escutar angústias, buscando resolvê-las, a fim de agir com resolubilidade em relação ao usuário ou à comunidade, devendo ser uma ação realizada a todo tempo nos locais prestadores de serviços de saúde ${ }^{(22)}$. Ademais, significa humanização do atendimento, levando acessibilidade a todos, e também se trata da escuta qualificada da demanda da usuária, oferecendo-lhe um atendimento resolutivo, e tornando a procura e a utilização do serviço de saúde o mais agradável possível ${ }^{(19)}$

\section{CONSIDERAÇÕES FINAIS}

A maioria das gestantes atendidas na Atenção Primária para a realização de seu pré-natal se mostraram-se satisfeitas e aprovaram o atendimento recebido, em especial do profissional enfermeiro, tanto no aporte teórico, sanando suas dúvidas e inseguranças, como em procedimentos mais técnicos, como no acompanhamento da vitalidade fetal e de esquemas medicamentosos.

Em contrapartida, o acolhimento recebido foi considerado de maneira negativa, evidenciando que as gestantes não se encontraram acolhidas na unidade de saúde, e inúmeros fatores são associados, como demora no atendimento e falta de 
empatia por parte de alguns dos profissionais.

É importante que tanto o profissional que atende a gestante diretamente, como os demais envolvidos levem em consideração a importância do acompanhamento durante o ciclo gravídico da mulher, proporcionando apoio necessário em seu processo de adesão e continuidade do pré-natal, reorganização psíquica quanto ao vínculo com o bebê, nas mudanças corporais e na retomada do planejamento familiar.

\section{REFERÊNCIAS}

1. Nunes JT, Gomes KR, Rodrigues MT, Mascarenhas MD. Qualidade da assistência pré-natal no Brasil: revisão de artigos publicados de 2005 a 2015. Cad Saúde Colet [Internet]. 2016 [citado 8 ago.2020]; 24(2): 252-61. Available from: DOI: $10.1590 / 1414-$ 462X201600020171

2. Cançado MS, Barbosa MA, Oliveira ES, Corrêa MS, Souza DN. Percepções de gestantes com o cuidado pré-natal em tempos de Zika Vírus, Brasil. Investigação Qualitativa em Saúde. Atas CIAIQ2018. [Internet]. 2018 [citado 8ago.2020]; 2: 4453. Available from:

https://proceedings.ciaiq.org/index.php/ciaiq2 018/article/download/1763/1716/

3. Brasil. Ministério da Saúde. Secretaria de Atenção à Saúde. Rede de Atenção à Saúde da Mulher e da Criança. Rede Cegonha. Brasília (DF): Ministério da Saúde; 2018. Available from: https://portalarquivos2.saude.gov.br/images/p df/2016/abril/19/2-a-Rede-Cegonha.pdf
4. Dias EG, Santo FG, Santos IG, Alves JC, Santos TM. Percepção das gestantes quanto à importância das ações educativas promovida pelo enfermeiro no pré-natal em uma unidade básica de saúde. Revista Eletrônica Gestão \& Saúde [Internet]. 2015 [citado 8 ago.2020]; 6(3): 2695-710. Available from:

http://periodicos.unb.br/index.php/rgs/article /view/22431

5. Sociedade Beneficente Israelita Brasileira Albert Einstein. Nota técnica para organização da rede de atenção à saúde com foco na atenção primária à saúde e na atenção ambulatorial especializada - saúde da mulher na gestação, parto e puerpério. São Paulo: Hospital Israelita Albert Einstein: Ministério da Saúde; 2019. Available from: https://atencaobasica.saude.rs.gov.br/upload/a rquivos/202001/03091259-nt-gestanteplanificasus.pdf

6. Dias EG, Anjos GB, Alves L, Pereira SN, Campos LM. Revista SUSTINERE [Internet]. 2018 [citado 12 ago. 2020]; 6 (1): 52-62.

Available from: file:///C:/Users/Flor/AppData/Local/Temp/3 1722-120187-1-PB-1.pdf

7. Rodrigues FR, Covos JS, Covos JF, Rodrigues BC. Pré-natal humanizado: estratégias de enfermagem na prepração para o parto ativo. Revista Saúde em Foco [Internet]. 2018 [citado 20 jul. 2020]; 10:112. Available from: https://portal.unisepe.com.br/unifia/wpcontent/uploads/sites/10001/2018/06/010_P R\%C3\%89_NATAL_HUMANIZADO.pdf

8. Félix RS, França DJ, Nunes JT, Cunha IC, Davim RM, Pereira JB. O enfermeiro no prénatal para mulheres no sistema prisional. Rev Enferm UFPE online. [Internet]. 2017 [citado 8 ago. 2020]; 11(1): 3936-47. Available from: 10.5205/reuol.12834-309821-SM.1110201731 
9. Santos LF, Brito SS, Mutti CF, Santos NS, Evangelista DR, Pacheco LR. Características do pré-natal na perspectiva de mulheres atendidas em unidades de atenção primária à saúde. Rev Enferm UFPE on line [Internet]. 2018 [citado 19ago.2020]; 12(2): 337-44. Available from: https://doi.org/10.5205/19818963-v12i2a230817p337-344-2018

10. Da Silva TC, Bisognin P, Prates LA, Wilhelm LA, de Bortoli CFC, Ressel LB. As boas práticas de atenção ao parto $\mathrm{e}$ nascimento sob a ótica de enfermeiros. Biblioteca Lascasas [Internet]. 2016 [citado 15 jul. 2020]; 12(1). Available from: http://www.index-

f.com/lascasas/documentos/lc0886.ph

11. Lakatos EM, Marconi $M$ de A. Fundamentos de metodologia científica. 8. ed. [3. reimpr.]. São Paulo: Atlas; 2019.

12. Nascimento LCN, Souza TV de, Oliveira ICS, Moraes JRMM de, Aguiar RCB de, Silva LF da. Theoretical saturation in qualitative research: an experience report in interview with schoolchildren. Rev. Bras. Enferm [Internet]. 2018 [citado 8ago.2020]; 71(1):228-33. Available from: http://dx.doi.org/10.1590/0034-7167-20160616

13. Bardin L. Análise de conteúdo. Lisboa: Edições 70; 2011.

\section{Sortica AC, Cardozo GH, Silva GL,} Azevedo M, Lemos NA (organizadores). Guia de pré-natal na Atenção Básica. Rio Grande do Sul. Secretaria de Estado da Saúde. 2018. Available from: https://atencaobasica.saude.rs.gov.br/upload/a rquivos/201901/09090527-guia-pre-natal-naatencao-basica-web.pdf

15. Martins QP, Ferreira GS, Aragão AE, Gomes FM, Araújo LM, Ferreira FI. S.
Conhecimentos de gestantes no pré-natal: evidências para o cuidado de enfermagem. SANARE [Internet]. 2015 [citado 15jul.2020]; 14(2): 65-71. Available from: https://sanare.emnuvens.com.br/sanare/articl e/viewFile/827/498

16. Brasil. Ministério da Saúde (MS). Protocolos da Atenção Básica: Saúde das Mulheres. Brasília, DF: Ministério da Saúde; 2016. Available from: http://bvsms.saude.gov.br/bvs/publicacoes/pro tocolo_atencao_\%20basica_saude_mulher.pdf

17. Moreira MA, Carvalho LL, Ribeiro PS. Percepção de gestantes sobre a atuação da enfermeira na assistência pré-natal: estudo analítico. Arquivos de Ciências da Saúde [Internet]. 2016 [citado 18ago.2020]; 23(1): 78-82. Available from: https://doi.org/10.17696/2318-

3691.23.1.2016.217

18. Afonso JA, Afonso KK, Jones KM. Percepção das gestantes frente ao pré-natal prestado pelo enfermeiro. RBPeCS [Internet]. 2015 [citado 8ago.2020]; 2(1): 22-6. Available from: revistas.icesp.br/index.php/RBPeCS/article/d ownload/28/22

19. Alves CN, Wilhelm LA, Barreto CN, Santos CC, Meincke SMK, Ress LB. Cuidado pré-natal e cultura: uma interface na atuação da enfermagem. Esc Anna Nery [Internet]. $2015 \quad$ [citado 25jul.2020];19(2):265-71. Available from: http://dx.doi.org/10.5902/2179769213230

20. Urasaki MBM, Silva NG, Albuquerque RS. Análise dos registros de enfermagem referentes à condição da pele de gestantes. Rev Enferm Atual In Derme [Internet]. 2019 [citado 29dez.2021];88(26):1-8. Available from: https://revistaenfermagematual.com/index.ph p/revista/article/view/107/439 
21. Luz AR, Martins TG, Barbosa AC, Queiroz ES. Acolhimento: uma reflexão sobre o conceito e realidade. Revista Eletrônica Gestão \& Saúde[Internet]. 2013 [citado 8ago.2020]; 4(2): 2225-2237. Available from: http://periodicos.unb.br/index.php/rgs/article /view/22950/16473

22. Ortigara EF, Carvalho MB Pelloso SM. Percepção da assistência pré-natal de usuárias do serviço público de saúde. Revista de Enfermagem da UFSM [Internet]. 2015 [citado 15jul.2020]; 5(4): 618-27. Available from:

http://dx.doi.org/10.5902/2179769213230
Submissão: 2021-02-15

Aprovado: 2021-05-11

\section{Agradecimentos}

Este estudo foi financiado pela Coordenação de Aperfeiçoamento de Pessoal de Nível Superior - Brasil (CAPES) - Finance Code 001.

DECLARAÇÃO DE CONFLITO DE INTERESSE

Não há conflito de interesses. 